\title{
sciendo
}

DOI 10.2478/sbe-2019-0058

SBE no. 14(3) 2019

\section{TOURISM OF THE FUTURE - AN ON GOING CHALLENGE}

\author{
VINTEAN ADRIANA \\ Lucian Blaga Universty of Sibiu, Romania
}

\begin{abstract}
:
The aim of the paper is to provide information based on data collected from the review of different reports about tourism, a fast moving and competitive industry, an ongoing challenge for the future when travelling is easier and the tourist has more choices and is more aspirational. We value the tourism of experience and that of niche, as the consumers are more cultivated and selective, traveling for self-discovery. New groups of consumers are willing to spend their hard-earned money for authentic travel adventure. Each experience is different and has psychological impacts, the authentic experience being obtained through identifying some new interactions of the tourist with the respective destination. Within this segment regarding the emotional impact we value the satisfaction of the tourists that is being influenced by some factors depending on the locations they had chosen. Luxury, culture, authenticity, experiences will shape the future in tourism. The digital technologies have become imperative in this competitive world and are shaping the traveler's experiences as they provide valuable information. Our longing for journeys will always make us spend more money due to the higher level of living and this will go on as the number of tourists is increasing as well as the countries that invest in tourism.
\end{abstract}

Key words: tourism of experience, niche tourism, competitiveness, innovation, prosperity

\section{Introduction}

Our lives are dominated by the continuous quest for our personal wellbeing, with greater emphasis on experience, skills and personal development. This is challenging in an experience economy when the travelers have become more interested in peoples' cultures, ways of life, food and environments.

Along the centuries so many events have got an impact on the touristic industry and travelling has become much easier because everything around us has changed.

Global economic prosperity has an unexpected impact and we have become more addicted to innovation. People are influenced by events that they wish to attend and the tourists have a wider array of choices and they value competition differently and in future destination brands be more reliable and viable. (Yeoman, Munro, \& McMahon-Beattie, 2006) 
The touristic industry has developed along the years and this was correlated with the development and spreading of the means of transport. Now more than ever before, the natural disasters, terrorist attacks, the economic crisis during the XXIst century are important factors that had influenced the touristic demand in different touristic destinations.

Important changes had an impact on classic touristic markets, the result being their increase in complexity and as geographic habitat, and in this way they turned from national into international. Now, within the context of unprecedented development of the internet, of online booking and information, of infrastructure, we can better embrace the world touristic market.

We must take into consideration the most important factors that have determined the development of tourism such as: growth of the income for population at a world level, changes regarding the travelers' options for the touristic destinations, extending the habits to travel, the increase of the number of countries and geographical areas included in the circuit, a strong demand and offer for Asia, Europe, New Zeeland, Australia, improvement for national legislation in many countries in order to stimulate tourism, continuous training for the staff, educating the population to consume touristic products. Capitals are clusters of culture and heritage attractions luring the tourist and they seem to adapt to global change and give unforgettable experiences. (Maitland R, 2014)

Considered to be one of the economic sectors that had to face the world economic crisis, tourism registered an annual moderate growth during 2010-2015.

The touristic competitiveness is improving in developing countries, mostly in Asia-Pacific region where more attractive destinations appear. This industry of tourism creates bridges among people and this is the result of increasing number of people who travel cross border and the global trends, among them those which adopt some policies that are less restrictive concerning the visa.

As far as tomorrow's tourism is concerned, this will be shaped by new trends because the today tourist is addicted to more complicated lives and has a fluid identity that makes him more demanding with the desire for constant change, for new experiences. Now, tourists have money and they are believed to have a fluid identity of a continuous change in our world where things are moving very fast and they will pay for every experience. (Yeoman 2012). There will always be a challenge for the destinations they choose within the context of the openness of the world economy. The tourists will be looking for novelty, will desire the thrills wherever he goes, they want vision emotion, places where romanticism can be breathed, they have become aspirational.

\section{Things to take into account}

- Organizations (UNWTO, OECD, Eurostat) make efforts to do their best and they have brought significant progress in the touristic area. They work to raise awareness of tourism as one of the world's largest economic sectors and they have done researches (country analysis, city analysis, benchmark reports, monthly updates) developing forecasting models, focusing on security and travel facilitation, crisis and sustainable growth. 
- New strategies appeared to increase competitiveness and enlarge the dimension of destination management. The updated technologies help destination management to be more efficient. (Teixera 2019)

- Studying the problem of global tourism it is important to notice that it had developed as technology made travel become easier and cheaper and the tourists improved their experiences.

- The powerful economy entails tourism growth by: (UNWTO,2019)

$>$ a favorable environment

$>$ strong demand for air travel

$>$ digital technologies shaping the traveler's experience

$>$ facilitation of visa

- Tourists who arrived had a boost of more than 60 times, up from just 25 million in 1950 to 1.6 billion in 2019 International tourist arrivals (overnight visitors) increased $4 \%$ in January-March 2019 as compared to the same period last year, below the $6 \%$ average growth during the past two years.

- The increase is seen in the Middle East (+8\%) and Asia and the Pacific (+6\%). Europe and Africa (both $+4 \%$ ) and the Americas (+3\%) have also witnessed an increase in arrivals during this first quarter of 2019.(UNWTO 2019)

- It is obvious that total export earnings from international tourism surged to USD 1.7 trillion in 2018, or almost USD 5 billion a day on average.

- It is true that international tourism (travel and passenger transport) accounts for $29 \%$ of the world's services exports and $7 \%$ of overall exports of goods and services.

- Japan made efforts for its promotion as a top destination through Yokoso strategy (welcome in Japan!) that was launched in 2003 by the prime minister. This happened because Japan needed an aggressive promotion and a regional revival; the campaign about visiting Japan 2003-2010 promoted at a national and international level through TV, mass media, marketing, outdoor advertising, discounts and welcoming cards of tourists granted to foreign tourists, participation to international tourism fairs, partnerships with other countries to promote mutual exchange among tourists; the strategy of celebrity as well as that of implanting advertisements embraced by many hotels and restaurants. The openness of a country's borders is the key to develop international tourism and Japan is a good example (Uzama, 2011)

- It is obvious that the destinations have changed too - 70 years ago, almost two thirds of tourists went to Europe; now they are being spread all over the globe. Among the countries that are investing in tourism most are the USA and China (WTTC - World Travel \& Tourism Council report 2018). In the next decade the forecast is for an average of $3.8 \%$ contribution to GDP per year and figures were forecasted to exceed 1.8 billion by 2030 . WTTC outlines that the tourism industry employs more than 300 million people worldwide, that means one in 10 people on the planet. This number is going to increase with 100 million additional sector-dependent jobs to be created by 2028; the number of air travelers is expected to come to 8.2 billion by 2037 . We will take into consideration the fact that technology and innovation will be having a tremendous impact on customer habits and expectations, by changing how we plan, book, undertake, and evaluate our travel experiences. (Wyman, 2019) 
- In 2028 it is forecast that among the countries with the highest rate of investments in the touristic area will be The Arab Emirates 8,6\%, Qatar 7,8\% and Bahrain 6,9\%. But more and more the cheap air travel, the transparency of digital media, the sharing economy and unexpected summer heatwaves have already started to change everything. We have more experiences to choose from than ever before. Celebrity chefs have made us all aspiring cooks and cookery schools can be found everywhere. Specialist courses teach us everywhere from Sicilian villas to Scottish castles. Nonflight travel: low-carbon holidays travelling by train, or a visit in Masdar Abu Dhabi, choosing a staycation within your own country, volunteering during your holidays, nomadic vacations, year-long adventures experiencing the unknown, are challenges for the tourists who are looking for experiences.

- People are exposed and influenced by events, they consider the holiday as a luxury product as far as they wish them over cars, houses, jewelry. Consumer prosperity entailed affordability and the desire for the best holidays.

- The future consists in joining a team of advisers with a very good know- how updated with the latest technology as human intelligence and the artificial one goes hand in hand. People need to experience and this means a segmentation on niches but also a combination of new technologies and at the same time keeping the human stamp.

In this respect in future we'll be more interested in the tourism of experience with emotional impact, (cruise tourism, the wedding tourism) and the tourism of niche.

\subsection{The Tourism of experience}

In this century we are inclined to show off through experiences, not through things and we use them to say something about us, about our personality.

The XXI st century brings travelers who are looking for experiences, not being interested only in places. The traditional explorers as tourists were replaced with those of the digital era and they are actors of a global movement that aims at learning by experience. Therefore, people establish their own reality, future being created live melted in an ongoing present, of genuine experiences. More and more tourism is related to knowledge, learning and assessment. The tourist who experiences is not passive but he is involved he is interactive, critical and creative. Our era is viewed as a new one: that of the experience economy where consumers are searching for extraordinary and memorable experiences. The journey in itself becomes important, not only the destination because the emotional level is what travelers are looking for: a good connection with the places. They will understand more, they will appreciate alternative ways of life, they will find the beauty of natural landscapes, they will look for activities that appeal to niche personal interests (Quintanilla,2018)

Each experience is different and has different psychological impacts. The experience of positive emotions with a purpose in life about some activities will be remembered for the rest of the life (Taylor 2018).

This tourism of experience comes with some characteristics that must be taken into account: (Trends HRB magazine) 
$>$ Thematic- based on a theme usually the intrinsic value of a brand/ destination visiting car factories, bizarre thematic parks...

$>$ Aspirational- offering the possibility of personal development

$>$ Instructive- with an important educational component

$>$ Authentic- the tourist lives the vibrant life of a destination, discovers traditions and customs

$>$ Entertaining- it is interesting of course

$>$ Participative- the involvement of the tourist who turns into an actor

$>$ Ethnical- incorporates the landscape and culture specific for the respective place

$>$ Personal- creates a unique personal connection with the place he visited

$>$ Creator of new value- adding value to the touristic steps and enriches it with information and testimonials

$>$ Surprising - beyond the tourist's expectations- the surprise element

$>$ Emotional-identifies an emotional trigger; a unique experience causes an emotional reaction- the wow factor

However, there might be a decline of some experiences that began due to excessive commercial use, of experience approach. The assault of social networks entailed a touristic effervescence which successfully promoted different brands, places and destinations but maybe determining a stronger approach towards self-notoriety detail.

When looking at the touristic reality, namely the experiences, we have to approach it through our emotions. Marketing strategies continue to sell any product or service as a unique experience, regardless the actors in tourism. Once a revolution in tourism, communication is now another way of online promotion, a participative marketing instrument, a barometer for the tour operators to stand on the millennials market. A romantic dinner, a weekend breakfast, access to spa is no longer a special experience regardless the social media, sites or leaflets available.

The authentic experience can be obtained through identifying some new interactions of the tourist with the respective brand/ destination. Travels have to be mainly projected for emotional experiences so that the tourist should consider himself to be in a special moment of his life and to repeat the experience in the same way, with the same intensity might be difficult. While experiences are extroverted, photographed, shot and related to the others live, emotions are private, are meant to bring amazement and joy before uploading them.

As regarding authentic experiences millennials are looking for uniqueness, they want to be part of the cultures, they travel for self- discovery, they want to set themselves apart by jumping in buses or trains, they want to be active in exploring, they want to repeat what they see on social media. They choose inspirational destinations on different continents mostly in Asia, Africa and USA.

African tourism is changing, it means raw experiences ( Powel 2017) the lure due to Instagram.: Kenya( Amboseli National Park, interaction with Maasai people, Mount Kilimanjaro) Zimbabwe (incredible bush destinations), Botswana( Okavango Delta.), Seychelle(the Indian Ocean lands of 115 granitic, coralline islands,) Zambia (Victoria Falls), Tanzania (The Serengeti National Park) Namibia(desert sand dunes), Madagascar( $5 \%$ of all plant and animal species in the world)Ethiopia (the 
story of the people)Uganda(mountain gorillas.) Morocco (enchanting markets, redcoloured buildings, beautiful oriental palaces).( Koutsky 2019)

Economic hesitations and hostile geopolitics have an impact on the evolution of hospitality industry and this can be seen as an inflexion. Tourists are more informed, sophisticated, fluid, chameleon like but always looking for the authentic. And authenticity has a "shot of offline". The touristic offer will be told, multiplied online and validated as emotion in the real world in a solitary way or with participants to the touristic act. It is true that tourism has always been a dream world but recently the importance of creating touristic emotional products has increased. Among the basic activities in accomplishing this objective we mention:

- The turning of the touristic infrastructure into unique, original attractions

- Enlarging the traditional offers by bringing services based on elements that give additional emotion and satisfaction

- Using modern technology to add increased reality within the real touristic space

Therefore, touristic products and services can be positioned much better within the emotional key but on the other hand, more brands, destinations being very on the up online have to reconsider their offers.

Within this segment regarding the emotional impact we value the satisfaction of the tourists that is being influenced by prices, environment, services, destination image, valuing a clean and tidy environment, picturesque icons, with friendly local people, all kind of facilities to satisfy the tourists. (Lee, 2009). Passengers feel satisfied with safety, cleanliness and hospitality, with cultural attractions. Culinary satisfaction is asking for famous bartenders and cooks able to come with menus in accordance with the destinations and the preferences of the customers. A cruise in Asia will offer a completely different menu, the same one in South America or Africa, in the Middle East. Even utopian cities like Masdar in Abu Dhabi that was meant to be an eco-city, an experiment for the future can be an interesting destination for travelers who are looking for experiences. A unique one they will find here, where they encounter eye-catching architecture combined with traditional design principles with leading-edge buildings and not only...

Most valued when we have the tourism of experience is the cruise tourism, a dynamic industry in evolution ready to bring again and again the experience of a wonderful, unforgettable holiday. The volume of passengers goes like: North America 54\%, Europe 26\%, Asia 15\%, Australia 5.4\%, mostly aged 47-50 ( D'Aoust in hosteltur.com)

The number of passengers has surged from 23.3 million in 2015 to 28.2 million in 2018 with an expected increase of $6 \%$ in 2019, which will bring the industry to reach 30 million passengers. 314 ships were in operation at the end of 2018 and more than 70 others are under construction for the next years. The activity keeps focused in The Caribbean Seas (the leading cruise market, $33.7 \%$ of customers), the Mediterranean and the Baltic, it is spreading throughout the world, from the distant Pacific Ocean to the shores of the China Sea, from Alaska to Patagonia. It is the Alaska cruise tourism that accounts for $5 \%$ of global cruise ship passengers, according to the Rain Coast Data report. (Resneck,2019) Abercrombie \& Kent's "In Search of the Polar Bear" Cruise stops in Norway's unusual and interesting Svalbard islands, Iceland, and Greenland offering unforgettable experiences. 
All four Oasis Class ships, the largest ships in the world, will have an impact on the travelers: "Symphony of the Seas", "Harmony of the Seas" or the newly "Amplified Oasis of the Seas" and "Allure of the Seas". The newest Royal Caribbean gamechanger, "Odyssey of the Seas", is the first ship to bring Quantum Class technology to highly rated ports of call Aruba and Curaçao. Many Caribbean itineraries in 2020-21 will include the most epic beach day ever at Perfect Day at CocoCay(https://www.cnn.com > travel)

More than 250 cruise ships are sailing world wide and it is Great Britain that owns around $5 \%$ of the total number. The largest ship "Freedom of the Seas" is a superb combination of superlatives belonging to Royal Caribbean ready to meet the highest demands of the travelers.

The selection of destinations has strong ties with the attributes and attractions that passengers can find on the cruise ship, so the intention of buying a product is determined by the itinerary and services offered on board (Xie, Kerstetter \& Mattila, 2012). High tech facilities available for the passengers are to be taken into account mostly that they have attracted lately a younger and more dynamic public. Regardless the season, the exotic destinations are the preferences for the clients whether young or middle aged. To this we must add exploration and expedition destinations as niche products, journeys to the Arctic and the North Pole, Svalbard, Alaska, North West Passage, Indonesian Archipelago Galapagos Islands...

The French cruise company Ponant Cruises and Louvre Museum joined to offer in 2020 more cruises based on culture and information included the possibility to visit Louvre Abu Dhabi. Such journeys will be offering lectures and discussions by department managers who will allow visitors to discover places and collections (hosteltur.com 2019)

Cruise holidays open doors to experiences never dreamt before, sailing to iconic cities and exotic shores, to challenging places. Travelling around the world has outlined the importance of the cruise tourism not only for experiences but also for the possibility to have good jobs.

The future trends for cruises will be the following:

1. More private islands included in the itinerary in the Pacific, the Atlantic, and towards the Arctic

2. More tourists who wish cruise vacation ( $48 \%$ among those who have never experienced a cruise affirmed that will be back).

3. Famous chefs attracting the tourists with special food

4. Expedition itineraries (Svalbard with its curiosities) With emotional impact is also The wedding Tourism

More and more people are interested in iconic weddings. This industry is an aspect of contemporary society that will always bring people together as far as they have higher demands and increased income. They are attracted by destinations such as Caribbean, Asia and Europe mostly. Wedding cruises have got popularity lately and they combine both weddings and honeymoons. Destination weddings have become a fashion on all continents with guests that range from the number of 50 to 200 or more in Asia, Africa and the Middle East. The 'white isle' of Ibiza or other islands have become perfect place for a bohemian wedding by the beach. A wedding in Turkey promises stunning views, tropical weather and delicious food. Iceland is also a good choice, Asian countries 
with luxurious hotels and pristine islands. We must also take into account Bora Bora, Abu Dhabi, Dubai, India, New York, Seychelles, Tenerife, Mallorca or islands with very few inhabitants like Calala in Nicaragua with endless activities and tailored experiences in secluded places.

At a global level, in future, probably that people will be looking for more unusual and challenging experiments and this will for sure entail segmentation on niche.

\subsection{The Niche Tourism.}

'Niche tourism' has been defined as that kind of tourism which emerged in recent years as a contrast to 'mass tourism. Niche tourism is attracting tourists who want to spend more money and it is different because these tourists are more cultivated, refined, selective. Born out of this elitist concept which is expensive too, this kind of tourism has become accessible to more and more customers due to the fact that they wish to have experiences and spend money on this. It is considered to be one of the sectors with the fastest growth in the domain. In our world the emphasis being more and more on the individual needs of the consumers, the demand for such vacations came as something natural. Examples of niche tourism are numerous: Gastronomic, hunting, fishing, wine, medical spa, eco, pilgrimage, extreme sports, widelife, cultural, shopping, nightlife and party, adventure and nature based, cultural and heritage, business tourism...

In niche tourism there are special interest groups who wish to have adventures and experiences too. It has increased in South Africa lately. Safari, diving with sharks, rafting, are no longer curiosities but have become part of the destination. Special interest tourism in Africa is mostly photographic, avi-tourism, gastronomy, safari, wilde life, wine, property, spa..

With a good impact is the Airbnb with a growing popularity and very good services. Chris Lehane is very optimistic about the service as it has managed to sell about two million bookings in Africa this year. This form "of people - to people travels" creates a healthy tourism because the guests share their passions looking for authentic and cultural experiences with the locals. More than 2 million guests have arrived in South Africa, and almost double the number of tourists across the whole black continent. Airbnb is viewed as being a more environmentally friendly, authentic way to travel that brings greater benefit to the local economies. In Africa the hosts have gained more than $\$ 260$ mil. so far. Other countries in Africa have considered guests arrivals growth more than double during the past years. The niche tourism brings money in African countries more than one might imagine, as tourists pay for every experience regardless the danger that surrounds them or the unusual journeys.

At the Travel Summit in Cape Town 2018 Christ Lehane stated that by 2028 the percentage for travelling in Africa will be $8.1 \%$ of the country's GDP. But countries like Nigeria, Ghana and Mozambique, Kenya will bring more tourists every year. The locals will take advantage by getting $97 \%$ of the charges, so their lives have already changed and brought an increase in their income.

CAO Tours and Events is an agency in Cluj Napoca Romania that has specialized in historical cultural and entertainment tourism and is appreciated as niche tourism. The 
team has made touristic packages around the mysterious vampire known all over the world. The tours are being offered in the maternal language of the tourists by experienced guides. There are three packages suggestively entitled: the Transylvania Fairy Tale, Discover Transylvania, Dracula and also a day in the beautiful city of Cluj Napoca.

Eturia in Romania has launched new travel concepts such as "Share A Trip" and "Single Traveler". More than 20000 Euro are being invested in high-tech and new destinations are being looked for all around the world. There are exotic personalized holidays: Seychelles, Mauritius, Zanzibar and the Dominican Republic, China, Peru, Argentina, Brazil, Madagascar, Malaysia. Eturia is offering a wide range of vacations, in more than 100 destinations, and a team of experts that travel constantly and knows exactly how to customize every holiday for every traveler. The journeys are authentic, the team has tailored travel experience, they are attentive to satisfy the customers.

With a good impact on travelers are several other niche tourism examples:

- $\quad$ Gambling tourism

Tourists are interested to visit cities, places where to enjoy entertainment, mostly those addicted to this kind of tourism

- Gastronomic tourism (or food tourism)

Regardless where they travel, tourists are interested in food whether they want experience with chefs or just for fun.

- Property tourism

More and more tourists want to buy properties in exotic places. Mostly, in Egypt, Mauritius, Spain, either to relax during longer periods of vacation or to retire when they got pensioned.

- Wedding tourism

The fast-growing destination wedding industry is today worth more than $\$ 80$ billion, and this means that it has become a luxury way to mix the ceremony and the honey moon, reaching $25 \%$ of the global wedding market.( Restanis,2018)

- Wellness tourism

As they become more preoccupied by health, the tourists come to a destination to get a transformation, to return home after they enjoy relaxation and get emotional balance.

- Wildlife tourism

Tourists are involved in activities such as safaris, viewing marine wildlife, photographing wildlife.

- Wine tourism

Tourists visit wine-growing regions and wine routes, vineyards, wineries (cellar tours and tasting rooms), wine festivals (France, South Africa)

- $\quad$ Art Tourism

It is related to the contemporary works of art, festivals, galleries, concerts, locations of famous artists.

- Cultural tourism

This kind of tourism normally occurs in urban areas where there is history, where there are historical places to visit, traditions, customs, rituals in communities all over the world.

- Environmental Tourism, - also referred to as Ecotourism, Sustainable Tourism and Responsible Tourism -mostly millennials are interested in this kind of tourism. 
- Film Tourism

As the entertainment industry has developed, more and more tourists are planning their holiday or visits exploring the effects of films. (Tunisia)

- Voluntourism (Volunteer travel or volunteering)

Travelers usually young enjoy to choose charity scenarios and they volunteer for this in the most unexpected places.

- Tourism of Luxury

We witness a century of luxury when the tourists are looking for something relevant, niche, experimental. This kind of tourism brings people with money who can afford everything and expect to be pampered. For some, luxury is a part of their every day life, it is a normality. For others it means special experiences; and others are CEO and do business (Dykins 2018). But more and more there is a shift from material to the experimental and luxury has become bound up in experiences rather than in things.

This kind of tourism comes with unforgettable experiences reserved only for Luxury Gold guests in most luxury hotels: 12 Apostles Hotel \& Spa (South Africa) is offering exquisite experiences. Ashford Castle boasts an award-winning spa and 350 acres of lush woodland where guests can partake in horseback riding, golf, fishing, cycling, tennis, falconry even zip-lining. In Venice, enjoy a private evening journey of Doge's Palace, the Gothic masterpiece, with a Local Expert. Discover the secrets of the Venetian Republic without the crowds. In a rare opportunity, get exclusive access to Jaipur's City Palace or in Cabo -One and One Palmilla, Mexico with stunning landscapes and velvet gloved treatments.

\section{Tourism in the future}

In the next years, the world will become addicted to technological development. The digital generation $Y$ or the Millennials will pay for unusual but attractive experiences. They will be looking for thematic restaurants wherever they travel, for leisure tourism after the stressful meetings, they will choose smartphones for planning the whole journey. They are the largest generation so far, endowed with a great influence about the way our future will be looking like. They got used to have the information they need using the intelligent smartphone always with them. They have learned that there are no secrets for them so they can find out everything because they know how to search. They are more educated and bent to travel, they have better taste for everything, they are more opened to globalization. They combine perfect experiences with personalization being attentive to all details. And this helps them in choosing the adequate destinations. Although we live in a divided world (ruptures within the UE, America First policy), economic global prosperity will entail growth in the touristic industry and companies will invest in innovation in order to reach more tourists through mobile channels. That is why the players on the travel market are giving more and more personalized offers by using Al and IOT. The tourists will be more addicted to digital assistants in organizing the holidays. Artificial intelligence will be used on apps and it will create patterns for personal preferences. Vocal services will be improved to get the function of preferred channels in order to find information. There is much expectation regarding the consumers towards the touristic suppliers to align the 
technologies so as to offer perfect traveling experiences. We also take into consideration the potential of large companies that provide technology in order to create performant experiences for the traveler. More competitive services will be available for tourists in our interconnected world. This explosion of innovation will bring profit for IT companies that offer sharing economy platforms and work out systems for touristic operators to interconnect and affiliate to mobile platforms. The tourists will get the information for everything they can imagine to have perfect experiences and by using the apps as for bookings in hotels and not only. (Hatton 2009). So far, the internet is considered to be of utmost importance for the traveler who wants an unforgettable holiday starting with booking the place and ending with giving good reviews. (Isabel, 2009).

Traditional agencies and those on line will be decreasing as the tourists are more interested to rely on digital assistance. Big companies that supply technological services will colonize the touristic industry (Google, Baidu, Alibaba, Amazon, WhatsApp, WeChat) and hold superiority by the volume of data or analytical system they use and are being continuously improved.

\section{There will be:}

- facial recognition on the-fly will replace gates, allowing free the movement of people

- $\quad$ our cloud-based profile will be shared with all foreign government border agencies.

- $\quad$ security $x$-rays will be shared between countries to allow screening as you fly.

- walking through one tunnel that sniffs, scans and sprays you and your bag simultaneously

- major hotels will charter driverless configurable pods to hurry guests home

- luxury car companies will release high spec driverless models

- wireless earbuds will provide automatic interpreting services

- travel experiences will be available in real time virtual reality

- mid-market hotels will rely increasingly on automatons to service rooms, making chambermaids a mark of a luxury hotel ( Wastnage 2016)

\section{What to expect in future?}

- According to a survey made by WYSE Travel Confederation that has been made among young people (57.000 young travelers all around the world) millennials and $Z$ generation are attracted more and more by exotic destinations and expect more than the free Wi Fi. Political and social problems are not obstacles for the travels but make them think where they are welcomed and therefore be careful what destinations to choose. (Chapman, 2018)

- The UNWTO is expecting an increase for touristic arrivals with $3 \%$ and $4 \%$ to the number of more than 1.4 bil. tourists. Europe will register a progress similar to the world average while Asia and the Pacific will classify between $5 \%$ and $6 \%$ increase mostly in emergent destinations ( Pololikashvili, 2019).

- In USA arrivals will come to $2 \%$ and $3 \%$ as compared to previous years.

- Africa comes to $2 \%$ and $5 \%$ after the increase of $7 \%$ in 2018 as some destinations will be visited again 
- The Middle East boasts with $4 \%$ and $6 \%$ after the $19 \%$ it had had during the previous years.

- $\quad$ The USA had 214.000 mil dollar revenue (2\% more than last year) and France 67 000 mil. (6\% more than the previous year).

- The next destinations concerning arrivals in 2019 were China, Italy, Turkey (44 mil tourists, $22 \%$ more) also Mexico, Thailand. It was a sustainable growth and tourism represented $7 \%$ of world exports with a faster increase than the export of goods during the last 7 years.

- The secretary of UNWTO highlighted the fact that one of the positive factors that stimulated international tourism was the facilitation of visas and he referred to the initiatives that were taken in India, Saudi Arabia, Qatar, Argentina, Brazil, Russia. Russia introduced the electronic visa in Kaliningrad and Sankt Petersburg.

- Tourists have priorities when travelling. A good internet connection and many options regarding traveling are outlined by results of the study made by AccorHotels and the Research Institute Gfk based on surveying 5.000 tourists to better get informed with the customs for journeys. : $47 \%$ of the respondents aged 18-24 have chosen a free good internet connection, namely $54 \%$ as compared to $40 \%$ for persons aged 50-65. The expectations are an important aspect of each journey. The survey made highlighted that the Spanish people hoped to discover another culture and its history $(66 \%)$ and changed their habits $(31 \%)$ and wanted to live interesting experiences. Surprisingly $19 \%$ of the participants have considered that the best travel companion is nobody else but himself/herself. $25 \%$ Germans, Americans, Indians who were polled prefer to travel by themselves. The difference of generation is very important too. More and more young people aged 18- 24 choose to travel by themselves. The idea to travel with employers or work colleagues is taken for granted only by Chinese travelers. Among them $40 \%$ do not exclude the possibility to travel with their employers and $48 \%$ are anxiously waiting to travel with their work colleagues.( AccorHotels)

- Technological giants such as Google, TripAdvisor and Booking compete for the "unique ring", a universal app that integrates all that is necessary to plan and book a holiday from inspiration phases in social networks to the reservation and acquisition of all components for the trip.

- Digitization in the next 5 years will go on having a great impact on demands as far as the IP networks are concerned. The global IP traffic will increase in 2021 reaching 3,3 Zettabytes annually with an interannual increase of $24 \%$.( VNI 2019)

- Booking, the giant in tourism technology with other platforms such as Priceline, Kayak, Agoda, Rental-Cars and OpenTable is interesting due to the two very clear things: first, that there is a saturation of apps on the market concerning booking, sharing experiences, good orientation. Secondly, it is imperative to develop a unique app able to handle all of them. Mireia Prieto, regional manager for Booking Spain presented the results of a survey with 21000 persons in 29 countries in order to find out the trends of the demand.

- The economic growth in Asia has entail the improvement of the middleclass level of living and so the local and regional tourism will have a rapid evolution even if 
this new class will have lower financial resources as families in USA or Europe. This means that they will pay less for ultra -personalized services and they will travel in groups and companies will focus on low cost offers and this means that touristic companies will take into consideration the adequate solutions.

- Luxury chains acknowledge priority to a more aspirational wellness than a technological one. The number of luxury trips all around the globe will rise by 2025 with some very different travelers (from the independent to most opulent ones) in exclusive places.

- Europe is heading towards travels among more transports with a single click. In this way by allowing passengers in any place in Europe to travel towards a final destination by different means of transport without interruptions, with no barriers in only one interline travel of multimodal transport. The project is managed by Indra which is an important world consultancy and tech company

- The EU announced the selection of two cities as European capitals for the intelligent tourism 2020, Malaga in Spain and Goteborg in Sweden and for prizes given to European cities for excellency as touristic destinations in accessibility, sustainability, digitalization, cultural patrimony and creativity.

- The USA and China remain the leading countries as investing in tourism (176.3 bil dollars according to the WTTC.) China decided that tourism had to become one of the economy pylons and the strategies adopted are: the opening towards the West, relaxation of free circulation policy for the Chinese population.

- The government in Aruba signed an agreement with WTTC for the implementation of a program to link the airline services with land transport by using biometrical data for the traveler. An easy and safe travel is created as an experience from the flight to hiring the car and the check in at the hotel. Travelers give their identity only once at the beginning of the journey as far as the data are being processed. Facial recognition is used in all checking points.

\section{Conclusions}

What the tourists want to do with their holiday time is different now as they are devoting their time to new challenges. They want to be physically challenged, mentally rejuvenated, professionally inspired. And the tourists will pay for all they want as far as money got another meaning for them. The tourists want to be satisfied and this means happiness and they are ready to invest more and more in travelling.

The tourist has entered a new era of technology and innovation with a tremendous impact by changing the way he plans, books or evaluates experiences. All he shares is in a social media driven world, where it is up to each of us how we do this.

Tourism will continue to be one of the main engines of the world economy. New destinations have increased competition, the consumer's profile has changed: he is more informed, interacting directly, looking for new experiences that will remain unique for the rest of his life, regardless where he chooses to travel. 


\section{References:}

Bruce R, 2019, The future of tourism in https://www.juliusbaer.com > future-mobility

Bruce R, 2019, The future of tourism is all about the experience, rejuvenation, adventure, fulfilment, in https://www.tomorrowstourist.com

Burdett M, 2018, The fastest growth will be in emerging economies in Asia, Africa and the Middle East in https://www. future-tourism.com

Burdett, G, 2018, The future of tourism in https://geographycasestudysite.wordpress.com

Carey M, July 1, 2019, the 2020 cruise itineraries in https://www.cntraveler.com > story > the-2020cruises

Conrady R \& Buck M, 2009, Trends and Issues in Global Tourism, Springer.com

George Richard, 2019, Marketing Tourism in South Africa,Oxford University Press, 2019

Hosany S Witham M 2011, Dimensions of Cruisers' Experiences, Satisfaction and Intention to Recommend in Journal of Travel Research (JTR) Dimensions of Cruisers' Experiences in https: journals.sagepub.com

Lee, T.H. (2009). A structural model for examining how destination image and interpretation services affect future visitation behavior: a case study of Taiwan's Taomi eco-village. Journal of Sustainable Tourism, 6 (17), 727-745.

Maitland R, 2014,Tourism in National Capitals and Global Change, Routledge, Taylor\&Francis Group Koutsky J, 2019, 10 best places to go in Africa and what to do there by in Smarter Travel, in https://www.judykoutsky.com > travel

Popolikashvili Z UNWTO International Tourism Highlights 2019

Powell A, Africa's New Tourism Draw: Experiences 2017 in Voice of America

Resneck J, CoastAlaskaSeptember 19, 2019 in https://www.ktoo.org > 2019/09/19 > even-more-.

Robinson, M. and Novelli, M., 2005. an Introduction. In Marina Novelli (ed.), Niche Tourism: Contemporary Issues, Trends and Cases. Oxford: Elsevier Butterworth-Heinemann.

Stoica S, Eturia Viitorul in Turism consta in imbinarea inteligentei umane cu cea artificiala"bursa.ro 11-09-2019.

Taylor S, Varley P, Johnston T, Adventure Tourism: Meanings, experience and learning Routledge 2013

Teixeira, Jesus S, Ferreira, Matos J T Multilevel Approach to Competitiveness in the Global Tourism Industry IGI Global, 2019

Uzama 2011, A Cross-Border Cooperation: Strategies for Marketing Sustainable Development Tourism in Northeast Asia, Amazon.com

Quintanilla C, The Rise of Experience Tourism and What It Means for the Leisure Industry in https://pro.regiondo.com > experience-tourism

Yeoman, Munro and Beattie Mc, 2006 Tomorrow's World, Consumer and tourist in

Journal of Vacation

Yeoman I 2012- 2020tomorrow tourism Chanel View Publication USA

Wyman O, Three Insights Shaping The Future Of Travel - Oliver Wyman in https://www.oliverwyman.com > insights

Xie, H. J., Kerstetter, D. L., \& Mattila, A. S. (2012). The attributes of a cruise ship that influence the decision making of cruisers and potential cruisers. International Journal of Hospitality Management, 31(1), 152-159.

https://www.royalcaribbean.com > guides > the-coolest-new-cruises-in-2020-

UNWTO World Tourism Barometer and Statistical Annex, May 2019

https://www.luxurygold.com

.https://amadeus.com > travel-industry > report >

Travel Daily News > post > top-and-emerging. Wedding destinations 
https://www.africantechroundup.com > chris-lehane.

https://www.africa.com > Travel

annual report Cisco Visual Networking Index (VNI) Global Forecast and Service Adoption 20162021.)

Report produced by Justin Wastnage Message Shapers Public Affairs Report produced for the Tourism Industry Expo 2016 an Exhibitions \& Trade Fairs event)

Global Trends in Wedding Tourism, 2019: Key Destinations, Traveler Types and Market Opportunities in 2019 (GLOBE NEWSWIRE)in ResearchAndMarkets.com's

Shaping the Future of Luxury Travel | Future Traveller Tribes 2030 in https://amadeus.com > travelindustry > report. 